\title{
ACERCA DE LAS IDEAS DESAMORTIZADORAS DE FLÓREZ ESTRADA
}

\author{
Elena Aguado Cabezas \\ Universidad de León
}

\section{Resumen}

Siguiendo la evolución de los conceptos económicos básicos del político e intelectual asturiano sobre la propiedad y sus límites, sobre los arrendamientos rústicos, sobre la política tributaria y sobre la deuda pública, se analizan aquí las propuestas que Flórez Estrada presentó como alternativa a la legislación desamortizadora de Mendizábal.

Su planteamiento presenta aspectos muy discutibles como la fórmula de asignación de tierras en enfiteusis, la determinación de los beneficiarios y el procedimiento para la ejecución de todo el plan. Los puntos débiles del proyecto fueron la causa de que, ya en su tiempo, dicho plan se considerara desde las filas liberales menos viable y eficaz que el de Mendizábal.

\begin{abstract}
Going on the basic economical aims of political and intellectual "asturiano" about de private property and its limits, the rustic lettings, the pay policy and public debt, Flórez Estrada proposals, introduced as the alternative to Mendizábal's desamortizadora legislation, are analysed hear.

His posement shows very discussable aspects such as: the way for the asignation of lands in enfiteusis, the determination of the beneficiaries and the procedure for the whole plan ejecution. The weak points of the project caused that, already then, that plan was considered from the liberal files less achievable and effective than Mendizábal's law.
\end{abstract}

La figura política e intelectual de Álvaro Flórez Estrada emerge en la primera mitad del siglo XIX, época en la que se perfila la revolución liberal española y, en consecuencia, las diferentes vías de ruptura con el complejo entramado institucional del Antiguo Régimen. El ilustre parlamentario y economista asturiano representa una de esas opciones de tránsito y construcción del liberalismo, fundamentada en la aportación teórica a los problemas de la política económica de su tiempo.

Dos parecen ser los objetivos de su trabajo como intelectual y parlamentario: el conocimiento y difusión del pensamiento económico clásico, esto es, de los principios con los que se estaba avanzando en Europa un modelo de desarrollo económico nuevo, y su adaptación crítica o asimilación parcial a la realidad española. Todo ello en medio de una 
trayectoria vital en la que la actividad política de Flórez Estrada precede a los resultados de su reflexión como pensador de la economía, pero que presenta una relación estrecha entre ambas actuaciones. No se trata de un economista profesionalizado en la especulación sobre la materia, sino más bien de un político que entiende - como todavía era habitual en el siglo XIX - que el desarrollo económico nacional no puede alcanzarse sin el concurso de los conocimientos y el análisis pormenorizado de los principios de la economía política, a la vez que contempla esta disciplina como una rama particular de la ciencia del buen gobierno, útil para los asuntos públicos.

El texto de Flórez Estrada más conocido en España es el artículo titulado "Del uso que debe hacerse de los bienes nacionales" publicado en febrero de 1836, unos días después de que viera la luz el decreto de desamortización de Mendizábal. Se trata de un escrito muy corto, cuya celebridad se debe a la polémica que suscitó en aquel momento, porque se oponía frontalmente al modelo desamortizador de Mendizábal (no a la conveniencia de la desamortización) y porque ha sido una cita muy común en toda la historiografía de la desamortización de la segunda mitad del siglo XX.

De esa circunstancia se han derivado dos consecuencias: primero, que muchos estudios sobre la desamortización eclesiástica han limitado la explicación sobre el significado de dicho proceso a la óptica de las "consecuencias previstas" por Flórez Estrada, funestos resultados que nuestro autor profetizó como una inevitable y segura "merienda de negros". En segundo lugar, la atracción ejercida por la propuesta de reforma agraria que se contiene en "El uso (...) de los bienes nacionales" ha oscurecido otras partes más brillantes y originales de la aportación teórica del autor y de su trayectoria política, que evolucionan desde posiciones librecambistas y agraristas a otras que Almenar ha calificado de "reformismo radical".

En cualquier caso, se advierten cambios notables en su pensamiento económico, nunca ajenos a una peripecia vital que corre paralela a la de la revolución liberal española durante la primera mitad del siglo XIX. Al final de ese recorrido se encuentra La cuestión social..., una obra en la que Flórez Estrada fija los principios que sustentan la propuesta anterior sobre los bienes nacionales y que incorporaría a las ediciones posteriores de su Curso de economía política, la obra capital del economista asturiano. 
En este artículo pretendemos abordar de forma crítica la propuesta desamortizadora de Álvaro Flórez Estrada, relacionándola con sus escritos anteriores y posteriores, así como con el modelo llevado a cabo por Mendizábal.

\section{De Asturias a Cádiz, pasando por Inglaterra}

Flórez Estrada irrumpe en la escena pública a partir de 1808, en su Asturias natal, como procurador de la Junta General del Principado y participando de forma decisiva en la formación de la Junta Suprema ${ }^{1}$. Lo más destacado de esta primera etapa es su combate por los principios liberales que le llevarían a redactar, entre otras cosas, un proyecto de Constitución y un ensayo sobre los beneficios de la libertad de imprenta. Las ideas que se vierten en aquellos escritos abogan por "la seguridad, la libertad y la igualdad de condiciones"2. La Constitución para la nación española se editó por primera vez en Inglaterra (Birmingham, 1810), junto con la Introducción para la historia de la revolución de España (Londres, 1810) y otra obra que interesa destacar ahora al objeto de nuestra reflexión: se trata del Examen imparcial de las disensiones de la América con la España (Londres, 1810, Cádiz 1812 y Madrid, 1814) ${ }^{3}$, en la que el autor desarrolló un primer modelo interpretativo del desarrollo económico español, partiendo de lo que considera su rasgo dominante: el atraso económico de España en términos absolutos y relativos, es decir, tanto al considerar su potencial de país agrario como en la comparación con otras naciones vecinas, especialmente Inglaterra.

El título de la obra respondía a una motivación inmediata, cual era el descontento creciente de los españoles de ultramar que estaba ins-

\footnotetext{
${ }^{1}$ Véase una biografía del personaje, especialmente de sus ideas y actuación política en los dos primeros periodos constitucionales, en Ch. Lancha, Álvaro Fórez Estrada 1766-1853 ou le libéralisme espagnol à l'épreuve de l'histoire, E.L.L.U.G, Université des Langues et Lettres de Grenoble, 1984. Un recorrido por su pensamiento económico se puede leer en el trabajo de S. Almenar Palau "Álvaro Flórez Estrada y la economía política clásica”, en E. Fuentes Quintana (director), Economía y economistas españoles.4. La economía clásica, Galaxia Gutemberg, Círculo de Lectores, Barcelona, 2000, p. 369-405. Una introducción biográfica con comentarios al perfil político y a las principales ideas del autor, de donde hemos tomado las citas que aparecen en este artículo, en M. Artola Gallego y L. A. Martínez Cachero (V. I y II), Obras de Alvaro Florez Estrada, Biblioteca de Autores Españoles, Madrid, 1958. Sobre la relación de Flórez Estrada con los hechos que se citan, ver F. Carantoña Álvarez, La guerra de la Independencia en Asturias. S. Cañada, Madrid, 1984.

${ }^{2}$ L.A. Martínez Cachero, op. cit., p. 315 (V. II).

${ }^{3}$ El título completo de la primera edición era Examen imparcial..., de los medios de su recíproco interés y de la utilidad de los aliados de la España. La segunda edición (Cádiz, 1812) y la tercera (Madrid, 1814) aparecen con un cambio de título, que resulta significativo, Examen imparcial..., de los medios de su reconciliación y de la prosperidad de todas las naciones. Aquí el autor ha añadido algunos apartados sobre "el papel moneda" (Capítulo VI de la III a parte), sobre "los empréstitos" y la forma de "satisfacer la deuda pública" (Capítulos VII y VIII), etc. Aquí seguimos la edición de L. A. Martínez Cachero, op. cit., p. 3-161.
} 
pirando sus primeros intentos de emancipación política, un asunto que preocupaba enormemente a los parlamentarios de Cádiz. La posición de Flórez Estrada es contraria a la independencia de las colonias americanas, pero lo más significativo de su aportación es que al analizar las causas del descontento encuentra las de la "decadencia" nacional y avanza una propuesta para superarla. Partiendo de una crítica radical a la política mercantilista, en la que se advierten los presupuestos de Adam Smith, realiza un diágnóstico de la situación señalando tres problemas esencia$\operatorname{les}^{4}$ : La restricción y monopolio (Sevilla y Cádiz) practicados en el comercio colonial había permitido la realización de grandes fortunas a determinados grupos sociales que las dilapidaron de forma negligente, sin crear verdadera riqueza. Además, nuestro autor argumenta que desde el siglo XV la política comercial y fiscal española había reasignado artificialmente los recursos hacia el comercio con Ámérica y en menor medida hacia las manufacturas; asignación ruinosa porque este reino poseía —en su opinión- mayores ventajas en el desarrollo de la agricultura. Por último señala los efectos perniciosos de la gran cantidad de plata traída a España, causa de la elevación de los precios en la península y de la pérdida de competitividad de los productos nacionales, cuya exportación resultaba imposible por ruinosa. Así mismo, estos hechos tendrían efectos negativos sobre la Hacienda pública y el precio del trabajo, de donde procederían otros problemas como una errática política tributaria o el de la despoblación, a los que se añadía el régimen de vinculación territorial $\mathrm{y}$ todo el orden institucional del Antiguo Régimen.

En consecuencia con el análisis anterior, la primera estrategia de desarrollo económico para España que plantea Flórez Estrada discurre por el librecambio y el agrarismo. En su opinión era necesario acabar con aquel tejido especulativo, creado en torno al comercio colonial, eliminando el proteccionismo y las restricciones, permitiendo el librecambio con las colonias y el resto del mundo, lo que a su vez haría posible conservar las relaciones de la península con las colonias americanas dentro de una misma comunidad política.

\footnotetext{
${ }^{4}$ Flórez Estrada organiza la crítica al mercantilismo en el Examen imparcial en tres capítulos de la parte tercera del libro, en los que va examinando lo que considera principios erróneos de la política española y sus respectivos efectos. Los títulos son: "Causas que principalmente contribuyeron a la decadencia de la nación española. Examen de la primera, a saber: el gran rédito que producía a los españoles el comercio del Nuevo mundo" (Capítulo III, p. 49-52); "Examen de la segunda causa de la decadencia de la nación española, a saber: las restricciones fuertes que sufrió el comercio de América no sólo por la exclusión de una gran parte de los españoles, sino por la exclusión de los extranjeros" (Capítulo IV, p. 52-78); "Examen de la tercera causa a la que atribuyo la decadencia de España, a saber : la gran cantidad de plata traída de América a la península" (Capítulo V, p. 78-93). Toda esta obra ( $2^{\text {a }}$ edición) se puede leer en L.A. Martínez Cachero, op. cit., p. 49-93.
} 
Ahora bien, la propuesta librecambista de desarrollo prioriza el de la agricultura sobre el resto de las actividades económicas.

Es igualmente un error creer que por falta de capitales, mientras no tengamos fábricas nos puede convenir el comercio de comisión. Si por falta de fondos no podemos ser de repente fabricantes y comerciantes, a lo menos podemos ser agricultores, que no vale menos. Para esto una nación no necesita más capital que brazos y terreno ${ }^{5}$.

Y es que ya en este primer sistema Flórez Estrada parece identificarse con Adam Smith al señalar que la verdadera riqueza es la producción real - condición que no reúnen el oro y la plata - al tiempo que relaciona la "prosperidad" (el crecimiento de la producción) con el mayor nivel de empleo que se pueda alcanzar, tanto en la agricultura como en "las artes y comercio". Como el sector agrario cumple una función insustituible en el sostenimiento demográfico - " "pues que la especie humana no se reproduce sino en razón de la abundancia y facilidad de su subsistencia, que depende inmediatamente de las primeras producciones y manufacturas que se consumen y no de la moneda que ni alimenta ni abriga al hombre"6 - a la agricultura compete también un papel estratégico en la expansión productiva ${ }^{7}$.

Este poblacionismo de base agraria que encontramos en su primer libro de economía se mantendrá básicamente entre los presupuestos de don Álvaro y en las principales propuestas de aplicación política que desarrollará años más tarde.

\section{Entre el exilio y la revolución}

Tras el regreso y el golpe de Estado de Fernando VII en 1814, Flórez Estrada fue procesado y condenado, por liberal, a la pena de muerte, la confiscación de sus bienes y la destrucción de todos los ejemplares de sus obras que se pudieran incautar. Lógicamente huyó de nuevo a Inglaterra y allí continuó la conspiración política y la escritura a favor de una solución constitucional para España. En esta etapa escribió la Representación a Fernando VII en defensa de las Cortes, publicada por primera vez en Londres, en 1818; todo un manifiesto constitucionalista donde

\footnotetext{
${ }^{5}$ L.A. Martínez Cachero, Obras de Álvaro Flórez..., p. 78, (V. II)

${ }^{6}$ Ibídem, p. 61 (V. II)

${ }^{7}$ S. Almenar Palau, op. cit., p. 382. El autor califica este esquema teórico de poblacionismo agrario como presmithiano y entiende que hunde sus raíces, entre otros, en el mercantilismo agrarista, así como en el agrarismo liberal.
} 
se reclama la libertad en todos los órdenes y donde vuelve a insistir en la necesidad de liberalizar el comercio con América.

Tras el pronunciamiento de Riego, nuestro protagonista regresó del exilio, siendo elegido diputado a Cortes por Asturias en la legislatura de 1820-1822. Como parlamentario en esta segunda etapa revolucionaria se ocupa principalmente de los aspectos relativos al asentamiento constitucional avanzado: la defensa de las libertades de los individuos versus las prerrogativas de la monarquía y de los estamentos privilegiados; en esta tarea se alinéa con las posiciones más radicales que encarna el grupo de los "comuneros". La necesidad de perfilar el régimen político constitucional y el escaso tiempo que tuvieron para ello los liberales son sin duda las causas de que el parlamentario asturiano no tomara posición frente a otras políticas de los gobiernos del Trienio.

Así, en octubre de 1820 se puso en marcha una legislación desamortizadora que comprendía la venta de bienes rústicos de los monasterios masculinos mediante subasta pública y admitiendo únicamente títulos de la deuda (vales reales) como instrumento de pago . No existe noticia de que Flórez Estrada interviniera en este debate para poner algún reparo u objeción al proyecto, cuyo perfil criticaría abiertamente en la siguiente etapa. Las enormes dificultades de estos años quizás le indicaran que no había llegado la hora de impulsar desde el Estado las medidas de desarrollo agrario que se derivaban de las ideas expuestas en escritos anteriores, sobre todo en el Examen imparcial.

Con la segunda restauración absolutista de Fernando VII, don Álvaro Flórez volvió a Inglaterra y después pasó a Francia; un exilio intelectualmente muy fructífero, porque en esos años escribió su obra capital, el Curso de economía política. En opinión del profesor Almenar Palau, al menos el grueso de la redacción de dicha obra debió realizarlo entre 1826-1828 y significó un punto de inflexión en la trayectoria del autor, ya que a partir de ahí, sin abandonar la actividad política, pasa a primer plano su trabajo en las diferentes revisiones y ampliaciones de la obra, así como los contactos para intentar publicarla en España ${ }^{8}$. Ocho ediciones de este trabajo (incluyendo una traducción al francés) vieron la luz entre 1828, fecha de la primera en Londres, y la muerte del autor que ocurrió en 1853 .

\footnotetext{
${ }^{8}$ S. Almenar Palau, op. cit., p. 377, 378, 385 y ss. Del mismo autor, "El pensamiento económico de Álvaro Flórez Estrada. Economía ricardiana y reformismo radical" en un estudio preliminar de su edición crítica del Curso de Economía política. Instituto de Estudios Fiscales, Madrid 1980.
} 


\section{Pensamiento económico y análisis social}

En el prólogo del Curso de economía..., Flórez Estrada declara su intención de divulgar, en España y América del Sur, "las ideas de los economistas más sabios de Europa", pero con el propósito crítico de ir corrigiendo sobre ellas lo que consideraba erróneo. El autor construye aquí un segundo modelo de desarrollo, inspirado en el estudio detenido de las teorías de Ricardo y sus principales seguidores, McCulluch y Mill, con los que comparte (además de principios) la idea de que los resultados obtenidos en el análisis general deben aplicarse a la política económica. Por eso, aunque esta obra no contiene un capítulo específico referido a España, sí existen propuestas de aplicación al caso nacional. Almenar ${ }^{9}$ señala que éstas giran en torno a tres asuntos de máximo interés en el segundo tercio del siglo XIX: el debate sobre las opciones proteccionis$\mathrm{mo} /$ prohibicionismo o librecambio, la redefinición del régimen de propiedad de la tierra, y la reforma de la Hacienda pública. Sobre los dos últimos aparecen en esta importante obra principios económicos que su autor convertiría en propuesta política a partir de 1836.

Por ello, sin entrar en detalles sobre el proceso que siguió su especulación o sobre las principales influencias intelectuales, nos detendremos aquí en las posiciones que Don Álvaró fijó en el Curso de Economía... respecto a tres temas concretos, que inciden directamente en ese programa de acción política al que nos acabamos de referir: la propiedad de la tierra, los sistemas de arrendamiento y sus propuestas sobre contribuciones y empréstitos.

\section{1.- De la propiedad y sus límites}

Sobre el derecho de propiedad se extiende en los capítulos IV y V de la parte segunda del libro, dedicada a analizar la distribución de la riqueza ${ }^{10}$. Al comienzo del capítulo el autor declara:

Aunque entro con desconfianza en cuestión tan ardua y delicada, no la esquivo por ser eminentemente social, y por tanto incumbencia del economista resolverla. (...) no quiero aventurar doctrina que no dimane de principios sólidos (...). El que Smith establece asegurando que el trabajo del hombre es el manantial de toda riqueza, aunque luminoso, no es por si sólo capaz a desenvolver la materia que nos ocupa.

\footnotetext{
${ }^{9}$ S. Almenar Palau, op. cit. (2000), p. 400.

${ }^{10}$ Flórez Estrada, Curso de Economía..., en op. cit., p. 115-123. Esta edición contiene los añadidos que el autor realizó en las diferentes ediciones. Por eso recoge sobre este punto las ideas que el asturiano expuso en un libro posterior titulado La cuestión social, o sea, sobre el origen, latitud y efectos del derecho de propie$d a d$, que vio la luz en 1839 y que provocó también una viva polémica con Ramón La Sagra.
} 
No obstante, partiendo de la afirmación del "sabio escocés" construye una excepción y una parte de su doctrina sobre la propiedad:

No existiendo riqueza alguna que no sea producto de la industria del hombre, ni propiedad que no radique sobre una riqueza, se deduce que el derecho enunciado trae su origen del trabajo. Se deduce también de modo más patente que la tierra y los restantes dones de la naturaleza, siendo producto exclusivo de la voluntad del Criador, no pueden convertirse jamás en propiedad del individuo.

Pero nuestro autor defiende la propiedad privada como un derecho natural del individuo, luego debe dejar muy delimitadas sus proposiciones:

...Nadie reprueba de mejor buena fe que yo la absurda doctrina de cuantos establecen nuevas bases sociales aboliendo el derecho de propiedad, el más importante y necesario de los derechos conocidos. Nadie rechaza con más cordial sinceridad que yo las deletéreas ideas del comunismo, del socialismo y de los sansimonianos, moral especialmente opuesta al derecho de propiedad, y, por consiguiente incompatible con la propia conservación (...). Lo que, por consideración al respetable derecho de propiedad yo reclamo, es que no se le de una latitud excesiva, (...) antinatural, (...) destructora de lo que se aparenta defender.

En efecto, el economista asturiano incidió varias veces en que un mal reparto de la propiedad era la causa de todas las revoluciones (por ejemplo la francesa) y que sus propuestas de reforma se orientaban a evitar el enfrentamiento entre las clases. Más tarde su argumentación se completaría así

Siendo indudable que la tierra no puede apropiarse, por no ser producto del hombre, no cabe fundamento sólido para oponerse a que el jefe del Estado sea el que la distribuya con arreglo a las leyes de la Creación en las que se apoya el derecho de propiedad.

\section{2.- Sobre las clases de arrendamientos rústicos}

Flórez Estrada analizó en el Curso de Economía todos los sistemas de arrendamiento que conocía se habían aplicado en la historia y fue estableciendo los defectos de cada uno de ellos. En su opinión, el arrendamiento tenía que cumplir dos condiciones:

$1^{\text {a }}$. Que los arrendatarios empleen suficiente capital para el oportuno cultivo de las tierras. $2^{\mathrm{a}}$ Que los arriendos sean de larga duración. La falta de capital para el conveniente cultivo de la tierra perjudica al propietario, pues la tierra que no se cultiva como corresponde cada año se deteriora más y 
más. Los arriendos de corta duración perjudican al colono retrayéndole de hacer mejoras costosas sin las que nunca una empresa agrícola llegará a ser medianamente lucrativa.

Una reflexión sobre el caso español, le permite mostrar las ventajas de los arrendamientos en grande:

Los arriendos en España, por falta de capitales, tienen el defecto de ser muy en pequeño. Así, el labrador carece de medios para dar a su familia constante ocupación en las labores de la heredad arrendada (...). Una labor en pequeño exige iguales faenas que una en grande. El labrador que dirige diez obreros, podría dirigir treinta o cuarenta. Si en el terreno arrendado por un colono estuvieran reunidas las heredades que se cultivan por tres, se ahorrarían muchos gastos de los que se efectúan en caminos, riegos y cercados. El labrador en grande economiza más que el pequeño en sus continuas luchas con el propietario, con el jornalero y con el consumidor (...). En una palabra, el labrador en pequeño nunca logrará disfrutar una suerte exenta de apuros y de ansiedad ${ }^{11}$.

En consecuencia con lo anterior, el sistema de arrendamiento preferido por nuestro autor es el de carácter enfitéutico, ya que en su opinión resolvía los problemas que había planteado previamente:

La enfiteusis, creando a favor del colono la casi propiedad, forma una clase de trabajadores poco menos interesados en cultivar la tierra ajena que si les perteneciera la propiedad. En dicho sistema (...) el colono por la renta que paga se hace copropietario de la finca, disponiendo del dominio útil, es decir, de las ganancias que de ella puede reportar.

La enfiteusis es el sistema mejor calculado para el individuo y la comunidad. Asegura al labrador la completa recompensa del trabajo y del capital empleados en cultivar la tierra ajena; y al mismo tiempo inspira al propietario la confianza más cabal de que su finca no se deteriorará y de que el colono con puntualidad le entregará el canon estipulado, siendo semejante sistema el que proporciona colonos más pudientes. Por ningún otro se reúnen con igual facilidad el interés del propietario y el celo del cultivador.

(...) Convendría establecer enfiteusis no perpetuas, sino temporales y bajo condiciones que inspirasen al colono completa confianza de que él o sus herederos obtendrían la recompensa de sus faenas, y al propietario seguridad de que a cierto plazo se aumentará la renta de la finca cuyo dominio útil provisionalmente se había cedido.

\footnotetext{
${ }^{11}$ Ibídem, p. 113-114.
} 


\section{3.- Sobre tributos y deuda pública}

Flórez Estrada concibe una reforma tributaria que gravite cada vez más en el impuesto sobre la renta de la tierra; también admite alguna contribución especial sobre consumos de lujo y sobre las herencias. Todo ello está relacionado con una distinción previa entre consumos productivos e improductivos:

La contribución inmueble, cuando se halla impuesta de modo que recaiga sobre la renta de la tierra, se toma de una riqueza regularmente destinada a consumos improductivos. Esta derrama no desalienta la industria, por cuanto la renta de la tierra no constituye los gastos de la producción. Un buen sistema, pues, de contribuciones debe pesar en su mayor parte sobre la propiedad inmueble.

Además, nuestro autor se apoya en los argumentos de Mill y de McCulluch para proporcionar otra fuente de ingresos al Estado, la que se derivaría de arrendar las tierras incultas, "por un canon módico". Con este método se favorecería el desarrollo de la producción, procurando "incalculables beneficios a la clase trabajadora". Entre las siete ventajas que según señala se seguirían del acotamiento y arriendo de baldíos, coloca en tercer lugar que

"en circunstancias muy apuradas, el gobierno vendiendo algunas tierras, lograría un recurso expedito sin necesidad de apelar al oneroso expediente de un empréstito nacional, ni al más perjudicial aún de crear papel moneda" ${ }^{\prime 2}$.

El economista asturiano dedicó todo un capítulo del Curso de economía (el XIV de la segunda parte) a rebatir las posiciones de quienes defendían como fórmula económica la emisión de deuda nacional y a demostrar los desastrosos efectos de esa política que no reparó en calificar de inmoral. Veamos algunas de sus afirmaciones más rotundas:

Los empréstitos obtienen el aplauso de los parásitos que participan de las insensatas prodigalidades de la Corte, de cuyo modo logran pasar una vida de ocio y profusión. El deplorable sistema de empréstitos se halla en consonancia con los inmorales proyectos de una nueva especie de especuladores de Bolsa, que en lugar de cambios útiles y productivos, no hacen sino compras y ventas ficticias.

...El capitalista, con el préstamo, liberta sus riquezas de todo recargo sucesivo sin que se vea sometido a formar en razón a sus facultades parte de la

\footnotetext{
${ }^{12}$ Ibídem, p. 318-319.
} 
renta nacional. (...) semejante sistema en lugar de emplear en la producción fondos improductivos, consume gran parte de los que eran productivos

Tras contradecir a Ricardo en algunas de sus apreciaciones sobre el tema recoge del autor inglés el siguiente pasaje:

"Una nación que se ha metido en dificultades inherentes al sistema de empréstito obraría sabiamente si se desembarazase de ellas vendiendo la parte de propiedad suficiente a extinguir la deuda"

Consecuentemente con todo lo anterior, Flórez Estrada concluye

"En atención a los incalculables sacrificios que el sistema de empréstitos lleva consigo, opino que sería muy ventajoso a un país redimir la deuda vendiendo la propiedad que al efecto se necesitase

\section{El regreso a la patria. La hora de la acción política}

A la muerte de Fernando VII en 1833 se abre en España un periodo de transición política, marcado por el problema de la sucesión dinástica dentro de la misma familia regia, que daría lugar a la primera guerra carlista y obligaría a la regente $\mathrm{M}^{\mathrm{a}}$ Cristina a buscar apoyos para el trono de su hija Isabel II en las filas del liberalismo. El primer resultado de esta situación fue el regreso del exilio de unos cuantos liberales y la instauración del régimen del Estatuto Real.

Flórez Estrada regresa a España en mayo de 1834 y se incorpora a la vida parlamentaria en julio de ese mismo año como procurador por Asturias en las Cortes del Estatuto. El nuevo Régimen, que significaba una indudable apertura respecto del absolutismo anterior, resultaba claramente insuficiente desde la perspectiva del constitucionalismo liberal. Fue desbordado por la crisis revolucionaria que estalló en el verano de 1835 y que obligó a la Regente a llamar a Mendizábal para hacerse cargo de un gobierno que canalizaría el levantamiento, insertando a sus principales actores en las instituciones (Cortes, diputaciones y ayuntamientos), en tanto que, paralelamente, se enfrentaría a los problemas más acuciantes del país: ganar la guerra al Carlismo y dar solución al problema de la enorme deuda pública del Estado, cuyo pago exigían los acreedores.

Para Flórez Estrada éste era el momento de la acción política, la oportunidad que no se le había presentado en el Trienio de llevar a cabo la "Ley Agraria de los pueblos". Dicha ocasión surge cuando Mendizábal, antes de proceder a la reforma política del régimen del Estatuto Real,

\footnotetext{
${ }^{13}$ Ibídem, p. 321-325
} 
decide emprender un proyecto de desamortización eclesiástica, legislando sobre la materia sin previa discusión parlamentaria, aunque tras haber obtenido un voto de confianza de las Cortes ${ }^{14}$. Como es bien conocido, el 19 de febrero de 1836 se publicaba el decreto de desamortización eclesiástica por el que quedaban sujetos a la venta los bienes de todo el clero regular, mediante subasta pública, y dando a los particulares dos posibilidades para hacer el pago de los remates: en metálico y en títulos de la Deuda, aunque en este último caso no todos los títulos se admitirían por todo su valor nominal.

La alternativa de Flórez Estrada al proyecto desamortizador de Mendizábal no se hizo esperar; está contenida en dos textos: el primero es el ya mencionado y escueto artículo que publicó el 28 de febrero de 1836 en El Español, titulado Del uso que debe hacerse de los bienes nacionales $^{15}$; el segundo es un folleto que lleva por título Contestación de don Álvaro Flórez Estrada a las impugnaciones hechas a su escrito sobre el uso que debe hacerse de los bienes nacionales ${ }^{16}$, en el que contestaba a dos fuertes críticas (firmadas por A. de A, una, y la otra por M. O. de Z.), que fueron publicadas a principios de marzo de aquel mismo año.

En la primera de las entregas el parlamentario asturiano presenta su alternativa, sin reparar en cuestiones de reglamento o en explicaciones sobre cómo llevar a cabo su plan. Tras aclarar que comparte con el gobierno la necesidad de emprender la desamortización, aunque no puede aprobar el método propuesto, presenta el suyo propio como

El único justo (...), compatible con la prosperidad futura (...), conveniente a los intereses de los acreedores (...), popular (...), que no perjudica a la clase propietaria y el único, en fin, por cuyo medio se puede mejorar la suerte de la clase proletaria (...).

La forma de argumentación que emplea se limita a afirmar la bondad y facilidad de ejecución de su propuesta, frente al caos, el dispendio, el fraude y la injusticia que, en su opinión, suponía el proyecto de Mendizábal.

\footnotetext{
${ }^{14}$ F. Tomás y Valiente (El marco político de la desamortización, Ariel, Barcelona, 1971, p. 77 y 88-89) 1lamó la atención sobre este procedimiento del voto de confianza como una "hábil maniobra" que le habría permitido a Mendizábal anular la oposición al decreto por el que se pusieron en venta los bienes nacionales. En realidad el procedimiento tenía un antecedente muy cercano: la instalación de ayuntamientos y diputaciones mediante los respectivos decretos, que las Cortes autorizaron a Martínez de la Rosa en abril de 1835. Por otra parte la petición que Mendizábal hizo a las Cortes el 31-12-1835, y que se votó casi por unanimidad, fue presentada para que se autorizase al gobierno a "proporcionarse cuantos recursos y medios sean necesarios a la más completa asistencia a la fuerza armada".

${ }^{15}$ Flórez Estrada, Del uso que..., en M. Artola, op. cit., p. 361-364 (V.I).

${ }^{16}$ Ibídem, p. 367-383 (V. I)
} 
En realidad su altenativa no está improvisada para la ocasión, sino que como apunta Almenar ${ }^{17}$ la idea fundamental se incardina perfectamente en la trayectoria de su pensamiento económico y en el modelo social y político que venía propugnando: siempre con el objetivo de impulsar el desarrollo económico español (como país "atrasado"), partiendo del sector agrario y en el marco político de la monarquía constitucional, propone que no se vendan los bienes nacionales y que se entreguen a los colonos - "clase proletaria", les llama en algunos párrafos, jornaleros en otras ocasiones - mediante la fórmula de arrendamiento de carácter enfitéutico

Con el sistema enfitéutico todas las familias de la clase proletaria serían dueñas del dominio útil de la tierra que cultivasen $\mathrm{y}$, por consiguiente, interesadas en sostener las reformas y el trono de Isabel, pues en ellas verían cifrado su bienestar ${ }^{18}$.

Como el dominio directo recaería sobre el Estado, este último conservaría su condición de propietario de los bienes nacionales y el conjunto de los mismos. El acuciante problema de la deuda pública - que exigía una respuesta inmediata, puesto que de la confianza de los acreedores y de la recuperación de crédito por parte del Estado dependía la victoria contra el Pretendiente y la consecución de la estabilidad constitucional - lo abordaba Flórez Estrada al comienzo mismo de su artículo, al declarar que el Estado debía asumir únicamente el pago de los intereses de la Deuda, en lugar de su entera devolución, aplicando a tal fin las rentas resultantes de los arrendamientos enfitéuticos.

Ahora bien, esta propuesta política supone la renuncia del economista asturiano a sus ya mencionados argumentos económicos contra el empréstito y el mantenimiento de una fuerte deuda nacional. Recordemos que al final de su especulación acababa optando por la solución de "redimir la deuda vendiendo la propiedad que al efecto se necesitase", como medida más ventajosa para el Estado.

Siguiendo el mismo texto, unas líneas más adelante el autor señala un aspecto esencial para la ejecución del proyecto desamortizador, pero que como argumento se puede volver en contra de lo que propone. Afirma que no se conoce exactamente el importe total de la deuda pública "ni el valor de los bienes hipotecados al pago", siendo esto último especialmente cierto. Pero si se desconoce el alcance de la masa de bie-

\footnotetext{
${ }^{17}$ S. Almenar Palau, op. cit., (2000) p. 401.

${ }^{18}$ Flórez Estrada, Del uso que ..., en M. Artola, op. cit., p. 363.
} 
nes, menos se podría calcular lo que rendirían arrendados en régimen de enfiteusis.

En consecuencia, no está claro que los acreedores pudieran cobrar sus intereses a corto plazo, siguiendo este sistema. Ciertamente, el economista asturiano había previsto ya en sus escritos anteriores que un aumento de la producción agraria, forjado desde el reparto de la tierra, permitiría también el justo aumento de las tributaciones. Pero ese, en el mejor de los casos, sería el resultado beneficioso del sistema a largo plazo, que debería contar además con una profunda reforma del sistema de contribuciones. No es fácil que los acreedores del Estado estuvieran dispuestos a esperar tanto y con tan escasas garantías.

Tal vez porque era consciente de este hecho, dedica el autor varios párrafos tanto a convencer a los propietarios de la tierra de que su sistema es el que verdaderamente defiende sus intereses como a tranquilizar a los acreedores. Sobre este aspecto, realiza una curiosa distinción entre la honradez y respetabilidad de los tenedores de títulos y "los especuladores" o "traficantes en papel de la Bolsa que serían los principales compradores de bienes nacionales"19. Resulta imposible, sin embargo, realizar tal distinción en la práctica; lo que sucede es que Flórez Estrada deseaba dejar claro que su propuesta respetaba y protegía los intereses de los acreedores y que no pretendía violentar el derecho de propiedad, ni enfrentar a la clase de jornaleros y proletarios con las anteriores. En escritos previos nuestro autor ya había defendido que las clases medias eran las más productivas y la garantía moral del Estado, de ahí que orientara sus argumentos preferentemente a convencer a esos grupos sociales de que su alternativa era la más coherente y provechosa a sus intereses. Pero, a la vez, este era el momento de aliviar la situación de los más débiles.

Una mayor concreción sobre este último aspecto y la explicación más larga de su alternativa se halla en en la Contestación a los dos artículos críticos ya mencionados y publicados en La Abeja entre los días 1 y 6 de marzo de 1836. En esta ocasión don Álvaro Flórez aclara:

En mi plan de arriendos enfitéuticos (...) excluyo absolutamente los urbanos, cuyo destino aunque sea de mucha importancia (...) por lo que mira a los ingresos momentáneos del erario, es insignificante con el destino de los primeros [rurales], siendo la distribución de éstos lo que constituye la Ley Agraria de los pueblos...

\footnotetext{
${ }^{19}$ Ibídem, p. 362-363.
} 
El plan que yo creo convendría se adoptase en España, no solamente por lo que toca a los predios rústicos que disfrutaba el clero regular, sino también por lo que toca a las fincas de establecimientos de beneficencia y a los terrenos baldíos y de propios, sería, con muy pocas variaciones, el adoptado en Toscana por el gran duque Pedro Leopoldo.

Así conformada la masa de bienes nacionales, el Estado debe arrendarla por periodos de 50 años, en lotes cuya cantidad de terreno ha de ser suficiente para "dar ocupación todo el año a una familia de nueve miembros", y bajo un canon anual "que no debería exceder ni bajar de la suma que se pagaba al convento hace 20 años" 20 .

Es decir, se trata de un proyecto global de reforma agraria puesto que alcanzaría a todos los bienes señalados, más los resultantes de una propuesta perfilada por don Álvaro con posterioridad: que el Estado se convirtiera en el único propietario de la tierra, mediante el mecanismo de adquirir progresivamente todas las fincas que los particulares fueran poniendo a la venta. Nuestro autor planteó que esta reversión de la propiedad particular de la tierra se realizara a partir de una ley que declarase el derecho de tanteo del Estado en la compra de las tierras que los propietarios desearan enajenar ${ }^{21} \mathrm{y}$ destinando una partida anual a las mencionadas adquisiciones.

Toda la propuesta es coherente con el principio ya expresado en el Curso de Economía... sobre la excepción que constituye la tierra en el derecho de propiedad, por tratarse de un bien natural, "tan inapropiable como las fuentes, los ríos y los mares" ${ }^{22}$. Pero la aplicación de estas ideas sobre la propiedad de la tierra a la alternativa desamortizadora presenta algunos puntos débiles o, al menos, muy discutibles en lo que se refiere al reparto de la tierra y sus beneficiarios, por un lado, y, por otro, a las cuestiones de procedimiento. La clave reside en los siguientes aspectos:

\section{La delimitación de lotes y el canon}

La escasa credibilidad que ofrecía llevar a la práctica el proyecto en muy poco tiempo, de forma sencilla, sin gastos ni fraudes, combinando los dos elementos más concretos de la propuesta: la ambigua característica de la partición en lotes — de los que únicamente se dice que han de

\footnotetext{
${ }^{20}$ Ídem, Contestación de don Álvaro Flórez Estrada a las impugnaciones hechas a su escrito..., en op. cit., p. 367-368.

${ }^{21}$ L. A. Martínez Cachero, Álvaro Flórez Estrada. Su vida, su obra política y sus ideas económicas. Instituto de Estudios Asturianos, Oviedo, 1961.

${ }^{22}$ Flórez Estrada, Curso de Economía política, en op. cit., p. 117
} 
dar empleo a una familia de nueve miembros, teniendo en cuenta el cultivo a que se dedique - , y el canon a cobrar a los enfiteutas, que tendría como base el que pagaban a los conventos 20 años atrás.

El profesor Fontana recoge la opinión del Conde de las Navas (decidido partidario de Flórez Estrada), quien matizó la propuesta de su correligionario asturiano, aclarando que las tierras serían divididas en dos calidades: las de fácil cultivo se entregarían a los labradores a enfiteusis; en cambio las que "necesitasen la inversión de grandes capitales para hacerlas productivas, se venderían" ${ }^{\text {"23 }}$. Pero si el mismo Flórez Estrada suponía que "la clase proletaria no bajará de doce millones, calculándose en catorce la población de España", parece bastante improbable que existieran para todos fincas de las tan productivas que no necesitaran más que "el trabajo del cultivador", es decir, de las que el conde de las Navas reservaba para entregar a enfiteusis.

Como el reparto equitativo y la cantidad de tierra de cada lote constituían un pilar básico de la propuesta desamortizadora de Flórez Estrada, si falla aquél peligra toda su construcción argumental, por muy atractivo que resulte el proyecto de reforma y su orientación solidaria.

Otro tanto ocurre en cuanto al cálculo del canon anual que deberían pagar los enfiteutas: su intención es que fuera bajo, puesto que hace partir la base de las rentas que cobraban los conventos dos décadas atrás. Flórez Estrada parece situarse en la idea de que el clero regular mantenía los arrendamientos baratos por ser antiguos.

Los arriendos de bienes pertenecientes a conventos y a familias de la antigua nobleza, eran generalmente los más equitativos por el hecho mismo del mucho tiempo que había transcurrido desde su otorgamiento ${ }^{24}$

Este extremo no está comprobado. González de Molina ha podido demostrar, para el caso de Andalucía y en las primeras décadas del siglo XIX, que "el comportamiento del clero regular con los arrendatarios fue idéntico al de cualquier perceptor laico: presionando al alza en los tiempos buenos y resistiendo la baja en periodos de crisis" 25 , es decir, un

\footnotetext{
${ }^{23}$ J. Fontana Lázaro, "La desamortización de Mendizábal”, en A. García Sanz y Ramón Garrabou, Historia agraria de la España contemporánea. 1. Cambio social y nuevas formas de propiedad (1800-1850), Crítica, Barcelona, 1985, p. 241.

${ }^{24}$ Flórez Estrada, Del uso..., p. 363.

${ }^{25}$ M. González de Molina Navarro, Desamortización, deuda pública y crecimiento económico. Andalucía 1820-1823, Diputación Provincial de Granada, 1985, p. 226. El autor aporta también la opinión vertida por A. Argüelles sobre el asunto en la sesión parlamentaria del 5-5-1835: "En general los monasterios y conventos siguen en sus arriendos y contratos las mismas reglas que los demás propietarios; y no se crea que cuando arriendan las posesiones lo hacen por menos de su valor ...". Esta opinión, por la fecha en que se produce, es
} 
comportamiento orientado a obtener el máximo beneficio, no a la beneficencia. Por nuestra parte hemos podido comprobar que, en la provincia de León, aunque era relativamente frecuente la figura del foro o arrendamiento a largo plazo, los monasterios que disfrutaban de los principales patrimonios agrarios tenían la mayor parte de los mismos (sobre todo las fincas más productivas) arrendados por periodos de seis a nueve años. El fuerte descenso de los ingresos por rentas no cobradas, que se advierte en las contabilidades monásticas tras la Guerra de la Independencia, hay que atribuirlo a la imposibilidad de los colonos para pagarlas, dado que han descendido tanto los precios de los productos agrarios que el valor de las cosechas no alcanza para hacer frente a todas las obligaciones y reservar una cantidad de especies para la siembra siguiente. A lo anterior se suma la contestación de algunos pueblos a través de sus concejos, discutiendo la legalidad de dichas cantidades ante los tribunales o sencillamente demorando los pagos. La crisis de las economías monásticas se acrecienta en los años veinte; después de la desamortización del Trienio, y, aunque le fueron restituídas las fincas a los regulares en 1823, abundan los testimonios de impago de rentas. Esta realidad no permite sostener que los monasterios mantuvieran arrendamientos bajos.

Si el canon propuesto por Flórez Estrada para los bienes procedentes de los regulares es discutible, al menos constituye una referencia. Pero su plan comprendía también las fincas de propios y baldíos; P. Marteles se pregunta, con acierto, cuál sería la base del canon en estos ca$\operatorname{sos}^{26}$. Nada aclara nuestro reformador agrario; unos años más tarde cuando se refiere a las fincas de propiedad pública adquiridas por el Estado mediante compra a los particulares, dice que deberían arrendarse "por una renta más bien módica que subida"27. Al margen de este aspecto, la propuesta de incorporación de bienes comunales no se podría haber realizado en los años treinta del siglo XIX sin lesionar intereses de algunos de los que Flórez Estrada más deseaba favorecer (arrendatarios, jornaleros, proletarios, colonos). El autor del proyecto los considera a todos productores agrarios, pero había explicado sus diferencias al analizar los dife-

completamente ajena al debate sobre las medidas desamortizadoras de 1836 , por lo que tiene mayor significado.

${ }^{26}$ P. Marteles López, La desamortización de Mendizábal en la provincia de Zaragoza (1835-1851), Tesis Doctoral defendida en la Facultad de Letras de la Universidad Autónoma de Barcelona, 1990. Este autor realiza una crítica a las posiciones de Flórez Estrada sobre la desamortización en dos capítulos diferentes, en páginas 459 a 475 y en otro dedicado a revisar los tópicos sobre la desamortización de Mendizábal en páginas 50 a 56.

${ }^{27}$ L.A. Martínez Cachero, op. cit. (1961), p. 230. Dicha cita procede de la obra de Flórez Estrada titulada La cuestión social, o sea origen, latitud y efectos del derecho de propiedad. 
rentes sistemas de arrendamiento y las innegables ventajas económicas del arrendamiento "en grande".

Es bien conocido el papel que jugaban las fincas y bienes de aprovechamiento comunal en las economías campesinas, especialmente en provincias como la de León donde, incorporados a las pequeñas explotaciones, constituían un complemento casi indispensable de supervivencia. Precisamente, Flórez Estrada menciona como ejemplo encomiable de gestión igualitaria de la propiedad el caso del valle del Curueño (León), donde los pueblos - siguiendo unas ordenanzas muy antiguas y estrictas - se repartían "los propios o comunes en un determinado número de suertes o quiñones, según el número de vecinos" ${ }^{28}$. No se debe perder de vista el carácter complementario de este tipo de predios, tanto más útil cuanto se añadían a explotaciones viables integradas por fincas propias y otras arrendadas a los monasterios o a los propietarios laicos. Tanto en esa comarca como en las demás había familias cuya supervivencia dependía mucho más que otras del acceso a los bienes comunales, dentro de un paisaje agrario dominado por las explotaciones pequeñas y dispersas.

Al generalizar el plan, siguiendo la propuesta de Flórez Estrada (bienes rústicos del clero, propios y baldíos...) no se sabe quién va a perder, porque la mayoría de los campesinos deberían recibir más tierra para que el empleo de la familia tipo fuera posible durante todo el año. Pero en ese caso no habría lotes suficientes para todos: jornaleros, arrendatarios más pobres, proletarios; y si en aras de la justicia estos últimos debían resultar favorecidos, los anteriores seguirían regentando explotaciones muy poco viables. En consecuencia, habría sido necesaria una mayor concreción sobre cómo llevar a cabo todo un proyecto de reforma agraria que, partiendo de la propiedad estatal de la tierra, deseaba evitar cualquier revolución o enfrentamiento entre las clases.

\section{La cuestionable facilidad de ejecución}

Si la fuerza de la alternativa de Flórez Estrada reside en que no se vendan los bienes del clero, su defensa se detiene en intentar convencer de la facilidad de ejecución que supone el plan por él presentado, frente a la complejidad del decreto de Mendizábal y la instrucción del 1 de marzo que lo desarrolla.

\footnotetext{
${ }^{28}$ Flórez Estrada, Contestación... (1836), en op. cit., p. 376.
} 
Sobre la venta de los bienes nacionales, afirmaba haber calculado ...los fraudes inevitables que ha de haber, (...) la depreciación del papel que ha de entrar en su compra, (...) el inmenso coste de la administración existente y la nueva, que todavía se nos anuncia, será creada para hacer las ventas y (...) los crecidos gastos de la tasación y de documentos o nuevos títulos que se han de expedir; gastos que por necesidad recaen sobre el vendedor y no sobre el comprador...

...Por el contrario, el plan sencillo de arrendamientos enfitéuticos, encargada su ejecución a las diputaciones provinciales sobre no ofrecer ninguno de los fraudes indicados, y deber verificarse por un coste incomparablemente menor que el del sistema anterior, tiene la ventaja de promover instantáneamente la riqueza nacional (...). El sistema enfitéutico puede llevarse a su complemento en pocos meses; el sistema de la venta no se completará en muchos años... 29.

Después de haber leído las objeciones de sus oponentes y gentes más próximas al proyecto del Gobierno, don Álvaro Flórez volvió a insistir en este tipo de argumentos

El gobierno para realizar mi plan no necesita valerse de empleados ni agentes faltos de probidad, cuya circunstancia es general (...). Para su completa ejecución no se necesita hacer ni un solo justiprecio, ni una sola tasación del valor en venta y en renta, ni hacer una sola subasta; formalidades todas que, sobre no servir más que para encubrir fraudes, no se hacen sin muchos gastos y muchas dilaciones. No necesita sino que uno o dos individuos de la diputación provincial, asistidos de otros del ayuntamiento del distrito certifiquen haberse enterado de la escritura de arriendo formalizada hace veinte años por el convento al que pertenecía la finca" 30 .

La intervención en las escrituras de arriendo y en las anteriormente formalizadas con los antiguos propietarios a fin de averiguar únicamente la renta que se pagaba por las fincas, debería ser atribución exclusiva de las diputaciones, contentándose la ley con señalar la cuota del canon anual que el colono hubiese de pagar al Estado, y la cuota de terreno que se le debiese arrendar... ${ }^{31}$

El primer aspecto a destacar es la supuesta sencillez de ejecución de todo el plan de reforma agraria. Aún ciñéndonos a los bienes procedentes del clero regular — que eran en aquel momento los nacionalizados y destinados a la venta - la formación de los lotes que proponía Flórez

\footnotetext{
${ }^{29}$ Ibídem, Del uso que..., en op. cit., p. 362.

${ }^{30}$ Ibídem, Contestación..., p. 381-382.

${ }^{31}$ Ibídem, p. 368
} 
Estrada implicaría como mínimo trabajos de deslinde, división de las fincas más grandes, concentración de las parcelas pequeñas y valoración de cada una de las rentas reales de cada lote resultante, ya que muchas fincas estaban gravadas con cargas de todo tipo. Todo ello no son simples operaciones en las que además no quepa la discrecionalidad de quien las realiza o cuya ejecución resulte inopinable. Después de ese trabajo habría que proceder a la designación de nuevos colonos, ya que en la mayoría de los casos no podrían coincidir con los anteriores. Nada se dice sobre los criterios de distribución de lotes, ni quién se haría cargo de tan delicado asunto. En cualquier caso no podía ser un proceso rápido, barato, de efectos inmediatos y en el que sólo tuvieran que intervenir un par de diputados provinciales y algún alcalde.

El estudio del proceso de desamortización eclesiástica, tal y como fue llevado a cabo, es aleccionador sobre estos aspectos. Las principales dificultades que tuvo el Estado en la ejecución de las ventas se registran en las dos primeras fases: la elaboración de los inventarios de bienes eclesiásticos (tras la nacionalización y ocupación de los conventos) y la administración de las fincas y rentas rústicas en tanto no se vendieran. Quienes hemos estudiado este aspecto $^{32}$ podemos afirmar que fue una tarea complicada: los eclesiásticos no colaboraron; sus archivos casi nunca estaban completos; las escrituras de arrendamientos anteriores presentaban a veces grandes dificultades de interpretación (el tipo de arrendamiento, la naturaleza de los censos, las cargas o gravámenes que pesaban sobre muchos predios, etc.); las explotaciones se habían dividido una y otra vez dentro de las familias de los mismos arrendatarios... Lo que nuestro protagonista considera legión inútil de empleados que consumirían dietas, resultó un número francamente escaso para ejecutar las tareas mencionadas; también fue corto el número de gestores que administraron desde el sector público los bienes nacionalizados —una parte no encontró comprador en todo el periodo- mediante contratos de arrendamiento que, desde 1836, celebró directamente la Administración con los particulares.

Parece claro que la desconfianza de don Álvaro en los funcionarios de Hacienda era irreductible. Pero tampoco se explica por qué confiaba tanto en que la actuación de las diputaciones y de miembros de los ayuntamientos sería diáfana y diligente. Las corporaciones provinciales

\footnotetext{
32 J. Bello, Frailes intendentes y políticos. Los bienes nacionales, 1835-1850, Taurus, Madrid, 1997. E. Aguado Cabezas, La desamortización de Mendizábal y Espartero en la provincia de León (1836-1851). Tesis Doctoral leída en la Facultad de Filosofía y Letras de la Universidad de León, 2001, p. 99-177.
} 
estaban sometidas a elección y en consecuencia no eran estables, característica que no resulta muy adecuada para ejercer las funciones que su plan les encomendaba. Además, la inestabilidad política del periodo provocaba cambios muy amplios en la composición de los equipos de diputados de una a otra convocatoria electoral. La participación de los ayuntamientos es coherente con toda la propuesta, pero todavía resulta más inexplicable que no le cupiera sombra de duda sobre su ejecutoria. De hecho, en muchos municipios se habían practicado privatizaciones de bienes de propios, durante la guerra de la Independencia, de legalidad más que dudosa. Así mismo, algunas de las medidas de la política agraria ideadas por los ilustrados españoles en el siglo anterior fracasaron, no por ser inadecuadas o inútiles, sino porque tuvo que ser encargada su ejecución a los ayuntamientos, cuyos miembros, como ha escrito Angel García Sanz, las utilizaron en beneficio propio ${ }^{33}$. Ciertamente, ya no se trataba de una instancia del Antiguo Régimen, sino de corporaciones locales elegidas, pero ello no suponía la desaparición de las viejas oligarquías. Es fácil que don Álvaro Flórez conociera bien ese pasado, tan influido como estaba en sus planteamientos teóricos por hombres como Jovellanos.

Ahora bien, aceptando sin reserva alguna que creía sinceramente en la propuesta, como en todo el proyecto, no es menos cierto que las diputaciones podrían haber sido un apoyo político de mucha importancia, del que carecía Flórez Estrada en otras esferas. De hecho las corporaciones de 1836 fueron sensibles a la propuesta: durante varios meses se sucedieron las comunicaciones entre las de varias provincias, para que se tomara resolución en cada una "sobre la conveniencia de dar en enfiteusis los bienes nacionales". Probablemente el interés de muchos diputados provinciales por una alternativa de intención tan solidaria no era ajeno a la parcela de poder que se abriría para las instituciones de gobierno provincial con la gestión que les encomendaba el proyecto del economista asturiano.

\section{La previsión sobre la subida de rentas}

Otro de los pronósticos que avanzó -y que tuvo más éxito en la historiografía que valora las consecuencias de la desamortización de Mendizábal- fue que si se vendían los bienes nacionales sólo comprarían los traficantes en bolsa y otros poderosos que inmediatamente subirían

\footnotetext{
${ }^{33}$ A. García Sanz, "La reforma agraria de la Ilustración: proyectos y resultados. El precedente del arbitrismo agrarista castellano", en A. García Sanz y J. Sanz Fernández (coord.), Reformas y políticas agrarias en la historia de España, Ministerio de Agricultura, Pesca y Alimentación, Madrid, 1996, p. 161-200.
} 
las rentas. Este hecho provocaría, en su opinión, la afiliación del campesinado al carlismo y consecuentemente se pondría en peligro la monarquía constitucional.

Se trata de una previsión realizada en 1836, cuando únicamente han sido nacionalizados los bienes del clero regular. La base de tal pronóstico la extrae nuestro autor de alguien que le participa desde Galicia

...que los que se afilian en las banderas de la conspiración son, por lo general naturales de los pueblos cuyas tierras pertenecían a los conventos, y que la causa primordial no es otra que el temor de que los compradores de aquellas tierras han de subir las rentas. Este sólo hecho debería hacer penetrarse a los acreedores del Estado de que su verdadero interés no debe aconsejar la venta de los bienes nacionales, pues sin que se consolide el nuevo sistema político jamás llegarán a gozar tranquilamente de los bienes nacionales que hayan comprado $^{34}$

Como ha señalado P. Marteles, lo único que prueba la primera parte del texto es la eficacia de los carlistas gallegos para alistar voluntarios ante el temor de que se subieran las rentas ${ }^{35}$. En esas fechas todavía no han comenzado las ventas, que siguieron un ritmo muy lento en los primeros años, para acelerarse a partir de 1839, precisamente cuando el final de la guerra carlista era inminente. Es posible que esa evolución tenga que ver con la desconfianza de los compradores en una situación política tan inestable, pero el escaso número de subastas realizadas en los primeros años se relaciona más con las dificultades apuntadas anteriormente en la formación de inventarios y en la puesta en marcha de toda el complejo mecanismo de transmisión de bienes.

Lo cierto es que todo el fundamento de que el plan desamortizador de Mendizábal arrojaría al campesinado a las filas del carlismo reside en el temor a la subida de las rentas. Esto último, sin embargo, no pudo ocurrir de inmediato ya que el Gobierno, mediante una R.O. de 21-41836, declaró que se respetaban todas las rentas hasta la finalización de los periodos de arriendo. De esta forma, aunque un propietario tomara posesión de las fincas adquiridas en subasta no podía "molestar al inquilino, ni pedirle mejora alguna mientras no cumpliese su contrato". Cuando finalizaba éste y la finca no había sido vendida, el Estado volvía a renovarlo por un máximo de tres años (según la misma orden ministerial) y, a partir de 1837, los contratos de arrendamiento entre la Administra-

\footnotetext{
${ }^{34}$ Flórez Estrada, Contestación...(1836), en op. cit., p. 374.

${ }^{35}$ P. Marteles, op. cit., p. 52-53.
} 
ción y los particulares se hicieron mediante subasta pública, tomando como tipo de salida la renta que venían cobrando los conventos. Por lo tanto, no coinciden los tiempos de alistamiento carlista y desarrollo de la guerra con la temida consecuencia de la elevación de rentas.

Son variados los factores que intervienen en la determinación de las rentas pero, ciñéndonos al periodo que nos ocupa, hay uno que se debe destacar: la normativa de arriendo de los bienes nacionales arbitrada por el Gobieno en 1837 y que estuvo vigente durante el resto del periodo desamortizador. La Instrucción de junio de ese año previno la rebaja "del cuarto", es decir, si nadie se interesaba por la subasta de las fincas anunciadas en arriendo se hacía una rebaja del $25 \%$ en el tipo de salida (cantidad del contrato anterior). Con esta medida los bienes nacionales se estuvieron arrendando en cantidades más bien bajas. Teniendo en cuenta que muchos no se vendieron en toda la etapa de la desamortización eclesiástica y que estuvieron constantemente engrosando la oferta de arriendos, pudieron contribuir a contener la subida general de rentas que por supuesto pretendían los compradores de la desamortización eclesiástica.

\section{A modo de conclusión}

En este brevísimo recorrido por el pensamiento y las propuestas de Flórez Estrada no hemos querido entrar en otras repercusiones que la alternativa desamortizadora de Don Álvaro conllevaba. Aunque el ilustre economista había evolucionado en el Curso de Economía... hacia un modelo de desarrollo no necesariamente agrarista, en el transcurso de la polémica desamortizadora se produce una nueva fractura en su pensamiento, que explicita en el folleto titulado La cuestión social, o sea sobre el origen, latitud y efectos del derecho de propiedad, de 1839. En esta obra y en la Contestación que dirige a su oponente Ramón La Sagra ${ }^{36}$, completa la propuesta de reforma, replanteando su modelo agrario: únicamente el Estado debe ser propietario de la tierra; niega la legitimidad de la propiedad privada de ese bien como la del resto de los recursos naturales y, en consecuencia, concibe la renta como una apropiación indebida, como una forma de explotación ${ }^{37}$.

Dicha estrategia de desarrollo económico, propuesta para la España del segundo tercio del siglo XIX, no contemplaba el desenvolvimiento de las relaciones de mercado y del capitalismo industrial. Recor-

\footnotetext{
${ }^{36}$ Se puede leer en M. Artola Gallego, op. cit., p. 387-406.

${ }^{37}$ S. Almenar Palau, op. cit. (2000), p. 401.
} 
demos que la experiencia histórica reivindicada por nuestro autor en repetidas ocasiones, como modelo de su alternativa sobre los bienes nacionales, era la reforma llevada a cabo en Toscana por el gran duque Pedro Leopoldo. Hoy sabemos que no fue precisamente esa región sino otras italianas las que iniciaron la industrialización en aquella península; para algunos autores las consecuencias del modelo toscano habrían conducido a "dos siglos de estancamiento económico"38; otros entienden que la supervivencia en esa región de la mezzadría (el sistema de arrendamiento a largo plazo, con división de dominio) es uno de los elementos más atrasados del feudalismo ${ }^{39}$.

Lo anterior no excluye que existieran otros modelos de modernización alternativos al del paradigma fuerte, que pone el acento de los perfiles de la modernidad en la gran industria, el desarrollo urbano, la burguesía capitalista, etc. Pero no debemos olvidar que el enfrentamiento de alternativas se produjo en los años treinta y cuarenta del siglo XIX, cuando se buscaba el desmantelamiento del Antiguo Régimen y una salida al modelo de desarrollo capitalista

Al abordar las ideas desamortizadoras de Flórez Estrada nos hemos limitado a analizarlas desde sus propios textos, para concluir que de ninguna manera se puede considerar su alternativa como más viable, más eficaz o con más perspectivas de futuro que el programa de desamortización de Mendizábal.

\footnotetext{
${ }^{38}$ J. Fontana, op. cit., p. 241. El autor se apoya sobre todo en los trabajos de Giorgio Giorgetti.

${ }^{39}$ Vése sobre todo V. Zamagni, "The rich in a Late Industrialiser: the Case of Italy, 1800-1945", en W.D. Rubinsdtein, Wealth and wealthy in de Modern World, Londres, 1980. Una interpretación algo diferente se desprende de R. Romanelli "A propósito de la burguesía. El problema de la élite terrateniente en la Italia del Ochocientos", en AYER La historia en el 90., Madrid, 1991, p. 44 y ss.
} 


\section{Bibliografía}

Aguado Cabezas, E. La desamortización de Mendizábal y Espartero en la provincia de León (1836-1851). Tesis Doctoral leída en la Facultad de Filosofía y Letras de la Universidad de León, 2001.

Almenar Palau, S. "Álvaro Flórez Estrada y la economía política clásica", en E. Fuentes Quintana (director), Economía y economistas españoles.4. La economía clásica, Galaxia Gutemberg, Círculo de Lectores, Barcelona, 2000.

Almenar Palau, S. "El pensamiento económico de Álvaro Flórez Estrada. Economía ricardiana y reformismo radical" en Curso de Economía política. Instituto de Estudios Fiscales, Madrid 1980.

Artola Gallego, M. y Martínez Cachero, L. A., (V. I y II), Obras de Alvaro Florez Estrada, Biblioteca de Autores Españoles, Madrid, 1958.

Bello, J. Frailes intendentes y políticos. Los bienes nacionales, 1835 1850, Taurus, Madrid, 1997.

Carantoña Álvarez, F. La guerra de la Independencia en Asturias. S. Cañada, Madrid, 1984.

Fontana Lázaro, J. "La desamortización de Mendizábal”, en A. García Sanz y Ramón Garrabou, Historia agraria de la España contemporánea. 1. Cambio social y nuevas formas de propiedad (1800-1850), Crítica, Barcelona, 1985.

García Sanz A. "La reforma agraria de la Ilustración: proyectos y resultados. El precedente del arbitrismo agrarista castellano", en A. García Sanz y J. Sanz Fernández (coord.), Reformas y políticas agrarias en la historia de España, Ministerio de Agricultura, Pesca y Alimentación, Madrid, 1996.

González de Molina Navarro, M. Desamortización, deuda pública y crecimiento económico. Andalucía 1820-1823, Diputación Provincial de Granada, 1985.

Lancha, Ch. Álvaro Fórez Estrada 1766-1853 ou le libéralisme espagnol à l'épreuve de l'histoire, E.L.L.U.G, Université des Langues et Lettres de Grenoble, 1984.

Marteles López, P. La desamortización de Mendizábal en la provincia de Zaragoza (1835-1851), Tesis Doctoral defendida en la Facultad de Letras de la Universidad Autónoma de Barcelona, 1990. 